\title{
Active and Reactive Power Flow Control using FACTS Devices
}

\author{
D. Murali \\ Research Scholar in EEE Dept., \\ Government College of Engineering, \\ Bargur-635 104, Tamilnadu, India.
}

\author{
Dr. M. Rajaram \\ Professor \& Head / EEE, \\ Government College of Engineering, \\ Tirunelveli-627 007, Tamilnadu, \\ India.
}

\begin{abstract}
Flexible alternating current transmission systems (FACTS) technology opens up new opportunities for controlling power and enhancing the usable capacity of present, as well as new and upgraded lines. The Unified Power Flow Controller (UPFC) is a second generation FACTS device which enables independent control of active and reactive power besides improving reliability and quality of the supply. This paper describes the real and reactive power flow control through a transmission line by placing the UPFC at the sending end of an electrical power transmission system. The power flow control performance of the UPFC is compared with that of the other FACTS device called Static Synchronous Series Compensator (SSSC). Simulations are carried out in Matlab/Simulink environment to validate the performance of the UPFC.
\end{abstract}

\section{Keywords}

FACTS, Matlab/Simulink, Real and reactive power, SSSC, UPFC.

\section{INTRODUCTION}

In today's highly complex and interconnected power systems, there is a great need to improve electric power utilization while still maintaining reliability and security. While power flows in some of the transmission lines are well below their normal limits, other lines are overloaded, which has an overall effect on deteriorating voltage profiles and decreasing system stability and security. Because of all that, it becomes more important to control the power flow along the transmission lines to meet the needs of power transfer. On the other hand, the fast development of solid-state technology has introduced a series of power electronic devices that made FACTS a promising pattern of future power systems.

Power flow between two buses of a lossless transmission line is given by :

$$
P_{i j}=\frac{V_{i} V_{j}}{X_{i j}} \sin \delta_{i j}
$$

where, $V_{i}$ and $\delta_{i}$ are the $i^{t h}$ bus voltage magnitude and angle, $V_{j}$ and $\delta_{j}$ are the $j^{\text {th }}$ bus voltage magnitude and angle, $X_{i j}$ is the line reactance. Thus, from the equation (1), it is clear that the power flow is a function of transmission line impedance, the magnitude of the sending end and receiving end voltages and the phase angle between voltages. By controlling one or a combination of the power flow arrangements, it is possible to control the active, as well as, the reactive power flow in the transmission line. With FACTS technology, such as Static Var Compensator (SVC), Static Synchronous Compensator (STATCOM), Static Synchronous Series Compensator (SSSC) and Unified Power Flow Controller (UPFC) etc., bus voltages, line impedances and phase angles in the power system can be regulated rapidly and flexibly. These FACTS controllers are based on voltage source converters. Thus, FACTS can facilitate the power flow control, enhance the power transfer capability, decrease the generation cost, and improve the security and stability of the power system [1]-[2].

A Static Synchronous Series Compensator (SSSC) is a member of FACTS family which is connected in series with a power system. It consists of a solid state voltage source converter which generates a controllable alternating current voltage at fundamental frequency. When the injected voltage is kept in quadrature with the line current, it can emulate as inductive or capacitive reactance so as to influence the power flow through the transmission line [3]-[5]. While the primary purpose of a SSSC is to control power flow in steady state, it can also improve transient stability of a power system [6].

The UPFC is a member of the FACTS family with very attractive features [7]. The UPFC is able to control, simultaneously or selectively, all the parameters affecting power flow in the transmission line (voltage, impedance, and phase angle) [8]. It is recognized as the most sophisticated power flow controller currently, and probably the most expensive one. The UPFC, which consists of a series and a shunt converter connected by a common dc link capacitor, can simultaneously perform the function of transmission line real/reactive power flow control in addition to UPFC bus voltage/shunt reactive power control [9][10]. The shunt converter of the UPFC controls the UPFC bus voltage/shunt reactive power and the dc link capacitor voltage. The series converter of the UPFC controls the transmission line real/active power flows by injecting a series voltage of adjustable magnitude and phase angle [11]-[13], on the other hand, the series part known as SSSC can be controlled without restrictions. The phase angle of series voltage can be chosen independently from line current between 0 and $2 \pi$, and its magnitude is variable between zero and a defined maximum value. The parallel part known as STATCOM injects an almost sinusoidal current of variable magnitude at the point of connection. In this paper, a single machine infinite bus system with and without UPFC has 
been simulated in Matlab/Simulink environment. The real and reactive power flow control performance of the UPFC has been evaluated and is compared with that of SSSC. The simulation results show the effectiveness of UPFC on real and reactive power flow control through a transmission line.

\section{FACTS CONTROLLERS}

The basic principles of the following FACTS controllers, which are used in the single machine infinite bus system under study, are discussed briefly.

\subsection{Unified Power Flow Controller (UPFC)}

The UPFC is made out of two voltage-source converters (VSCs) with semiconductor devices having turn-off capability, sharing a common dc capacitor and connected to a power system through coupling transformers. The basic structure of UPFC is shown in Fig.1. The shunt converter is primarily used to provide the real power demand of the series converter at the common dc link terminal from the ac power system. It can also generate or absorb reactive power at its ac terminal, which is independent of the active power transfer to (or from) the dc terminal. Therefore, with proper control, it can also fulfill the function of an independent advanced static VAR compensator providing reactive power compensation for the transmission line and thus executing indirect voltage regulation at the input terminal of the UPFC.

The series converter is used to generate a voltage at the fundamental frequency with variable amplitude and phase angle, which is added to the ac transmission line by the series connected boosting transformer. The inverter output voltage injected in series with the line can be used for direct voltage control, series compensation, phase shifting, and their combinations. This voltage source can internally generate or absorb all the reactive power required by the different type of controls applied and transfers active power at its dc terminal. The reactive power is generated/absorbed independently by each converter and does not flow through the dc link [14]-[15]. The dc link provides a path to exchange active power between the converters. The series converter injects a voltage in series with the system voltage through a series transformer. The power flow through the line can be regulated by controlling the magnitude and angle of the series-injected voltage. The injected voltage and line current determine the active and reactive power injected by the series converter. The converter has a capability of electronically generating or absorbing the reactive power. However, both the series and shunt converters can independently exchange reactive power with the ac system. However, the injected active power must be supplied by the dc link, in turn taken from the ac system through the shunt converter. When the losses of the converters and the associated transformers are neglected, the overall active power exchange between the UPFC and the ac system becomes zero [16]-[17].

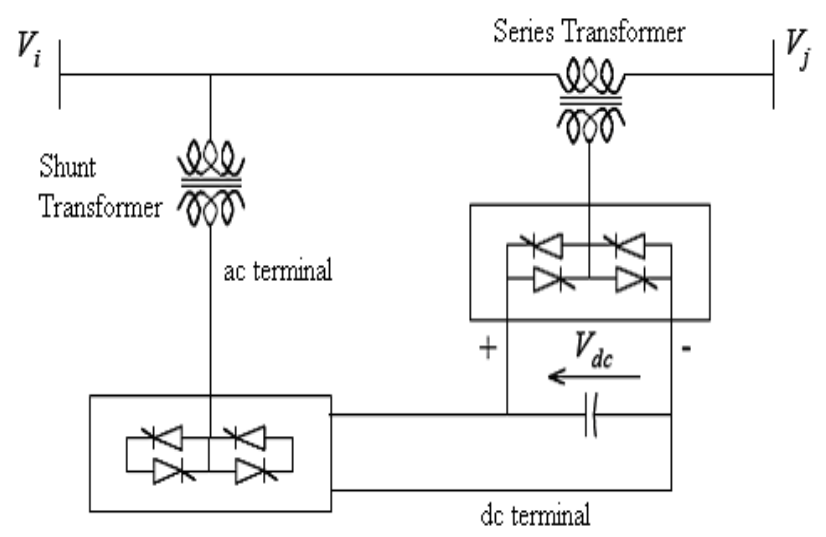

Fig. 1 Configuration of UPFC

\subsection{Static Synchronous Series Compensator (SSSC)}

The SSSC is one of the most recent FACTS devices for power transmission series compensation. It can be considered as a synchronous voltage source as it can inject an almost sinusoidal voltage of variable and controllable amplitude and phase angle, in series with a transmission line. The injected voltage is almost in quadrature with the line current. A small part of the injected voltage that is in phase with the line current provides the losses in the inverter. Most of the injected voltage, which is in quadrature with the line current, provides the effect of inserting an inductive or capacitive reactance in series with the transmission line. The variable reactance influences the electric power flow in the transmission line. The basic configuration of a SSSC is shown in Fig.2.

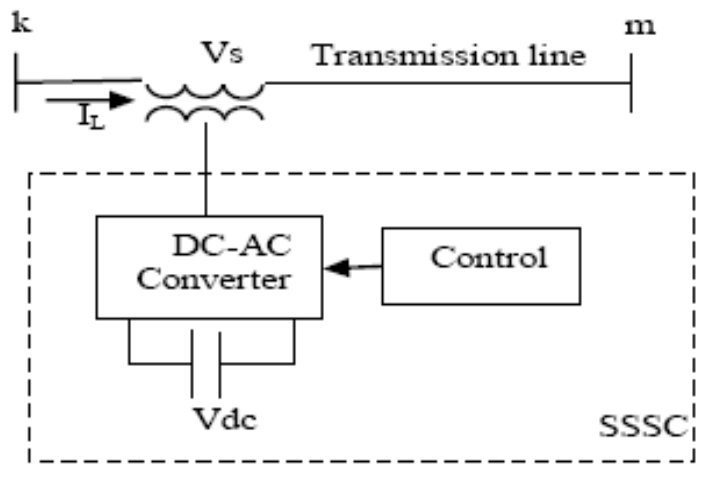

Fig. 2 Simplified diagram of a SSSC

\section{POWER SYSTEM MODEL}

Consider a single machine infinite bus (SMIB) system with series FACTS devices as shown in Fig.3. Here, the series FACTS devices such as UPFC (combination of STATCOM and SSSC) and SSSC are equipped between bus- 2 and bus- 3 . The UPFC installed between bus- 2 and bus- 3 effectively controls the power flow from sending end to receiving end. Here, $V_{S}$ and $V_{R}$ are assumed to be sending and receiving end voltages. This model assumes that sending end corresponds to a power plant while the receiving end to an electric power network, i.e., SMIB system. The system data are given in [18]-[19]. 


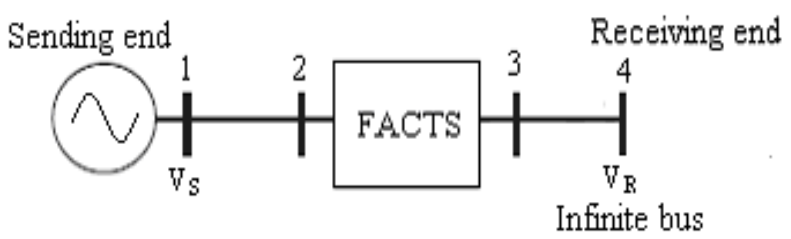

Fig. 3 SMIB system with FACTS device

\section{SIMULATION RESULTS DISCUSSION}

AND

A simple single machine infinite bus (SMIB) power system model as shown in Fig.3 is simulated in Matlab/Simulink environment. The FACTS device is placed in series with the transmission line at the sending end. The variations in power angle, active power and reactive power in the transmission line without FACTS device, with UPFC and SSSC are studied and compared.

When the system is without any FACTS device, the power angle oscillations can not be controlled as shown in Fig.4. However, when the transmission line is with UPFC or SSSC, the power angle oscillations are reduced as shown in Fig.5 and Fig.6.

Similarly, when the system is without any FACTS device, the amount of real and reactive power flow is low as shown in Fig.7, Fig.10, Fig.13, and Fig.16 respectively. However, the transmission capability of the existing transmission line is highly improved with the presence of UPFC than with the presence of SSSC as shown in Fig.8, Fig.9, Fig.11, Fig.12, Fig.14, Fig.15, Fig.17, and Fig.18 respectively. But the difference between the sending end and receiving end real power is high in the transmission line with UPFC or SSSC. This is due to the increase in the transmission line losses, which include losses in the converters and coupling transformers. The power transfer capability of long transmission lines is usually limited by their thermal capability. Utilizing the existing transmission line at its maximum thermal capability is possible with UPFC.

The series inverter injects voltage of variable magnitude and phase into the transmission line at the point of its connection, thereby controlling real and reactive power flow through the line. The active power flow through the line is supplied by SSSC. This real power is obtained from the DC source connected to its DC terminals. The shunt inverter provides the required power to the series inverter through the DC link.

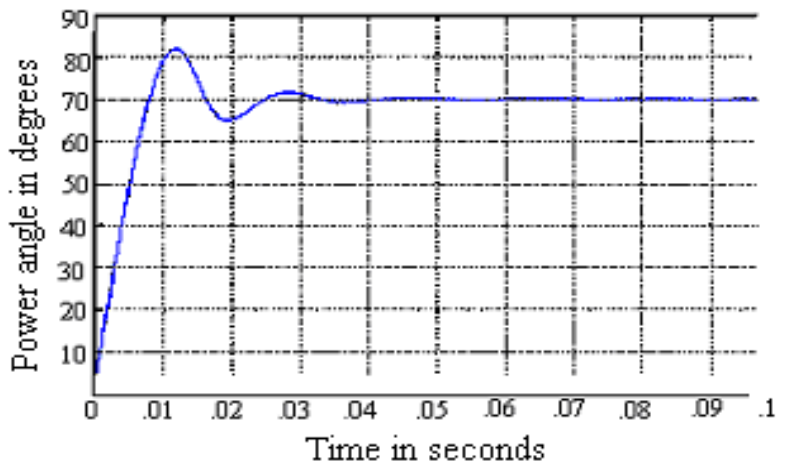

Fig. 4 Variation of power angle with time for the SMIB system without FACTS device

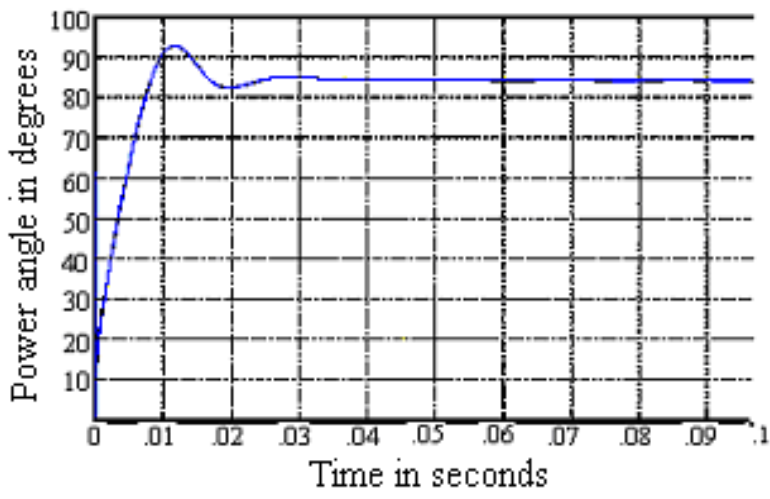

Fig. 5 Variation of power angle with time for the SMIB system with UPFC

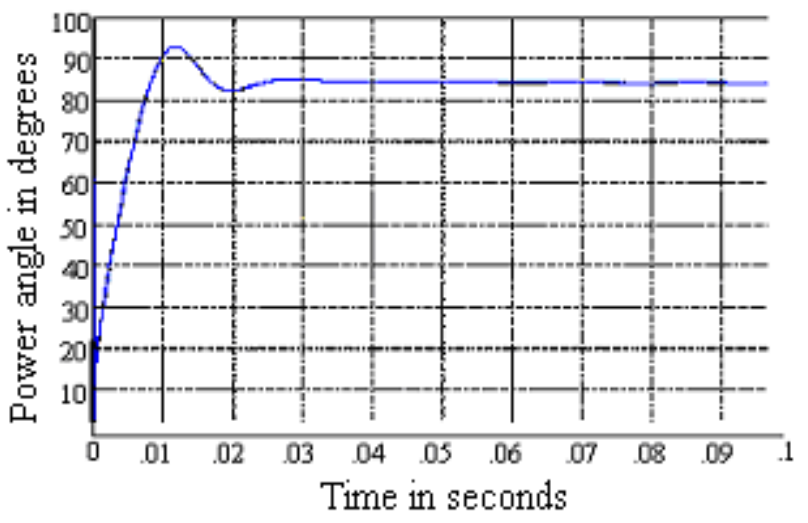

Fig. 6 Variation of power angle with time for the SMIB system with SSSC

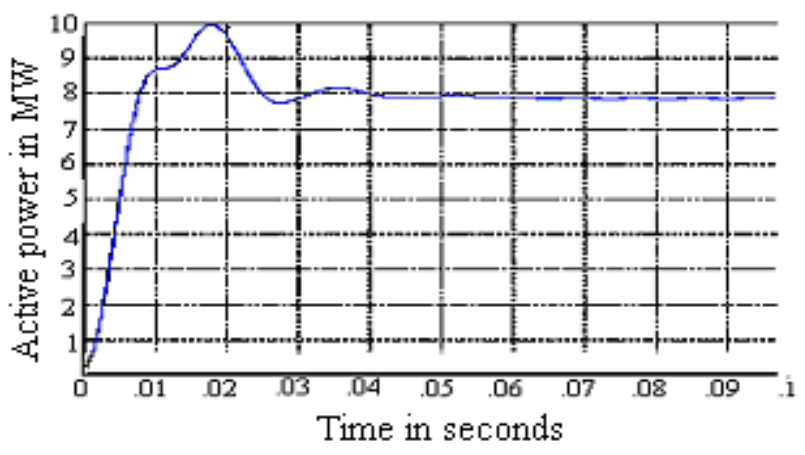

Fig. 7 Variation of sending end active power with time for the SMIB system without FACTS device 


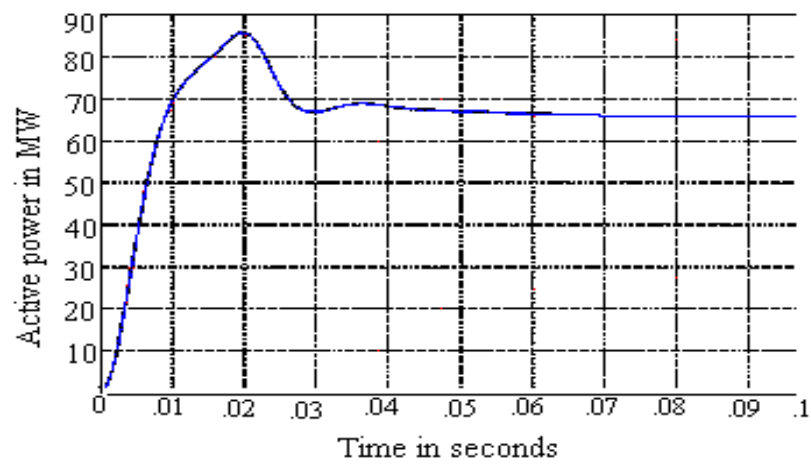

Fig. 8 Variation of sending end active power with time for the SMIB system with UPFC

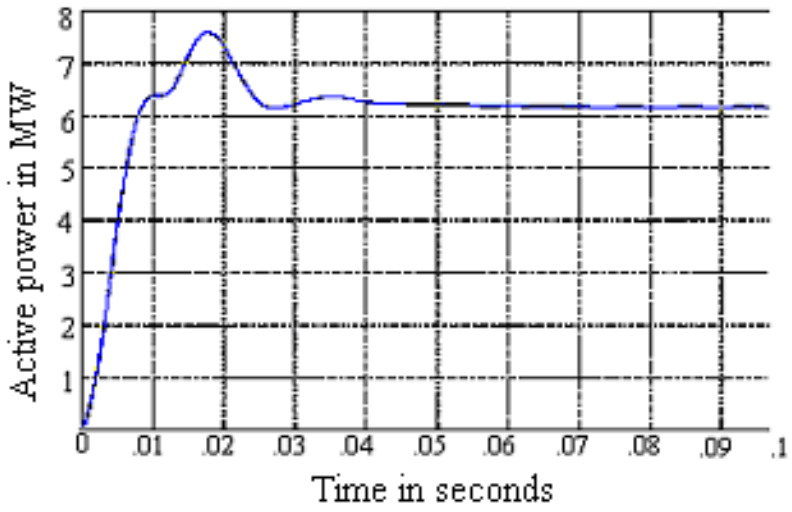

Fig. 9 Variation of sending end active power with time for the SMIB system with SSSC

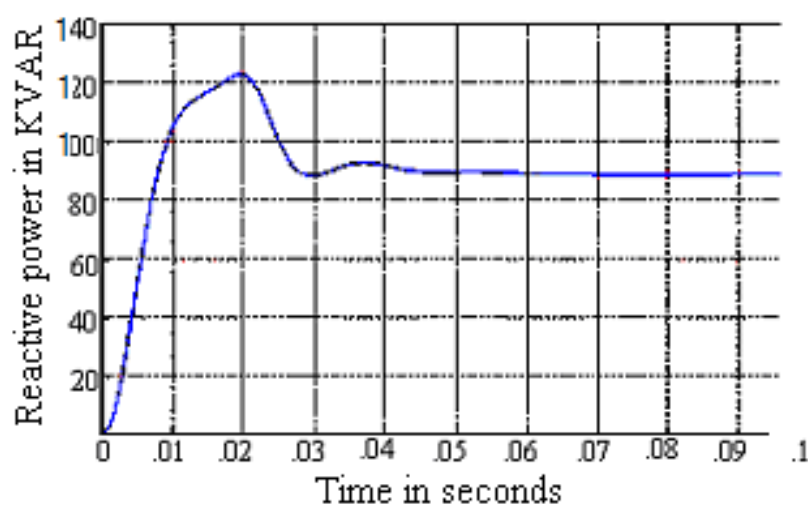

Fig. 10 Variation of sending end reactive power with time for the SMIB system without FACTS device

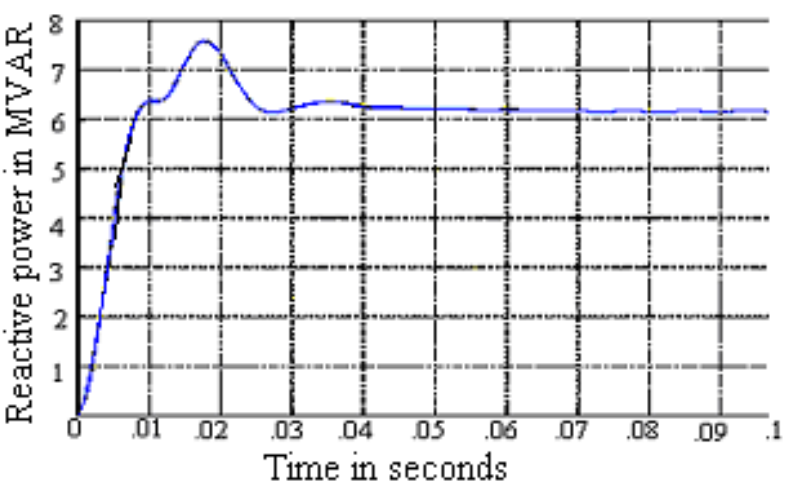

Fig. 11 Variation of sending end reactive power with time for the SMIB system with UPFC

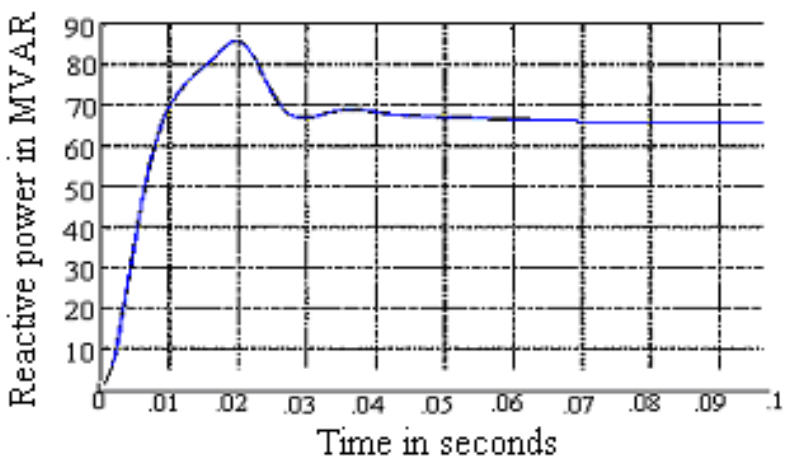

Fig. 12 Variation of sending end reactive power with time for the SMIB system with SSSC

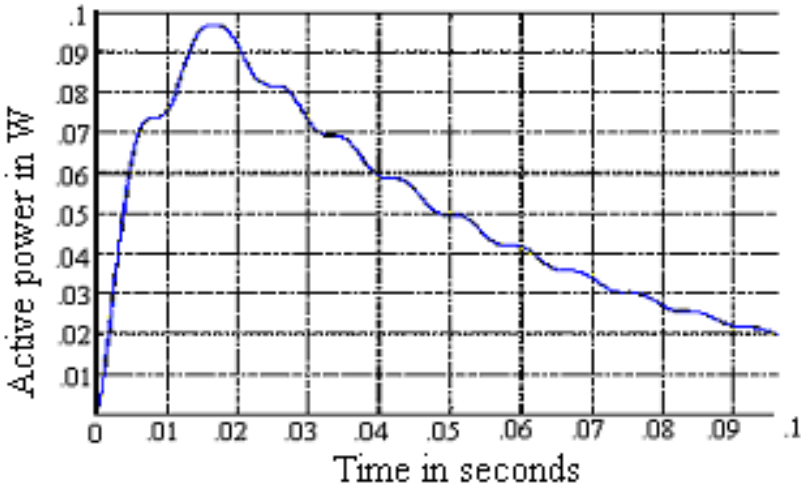

Fig. 13 Variation of receiving end active power with time for the SMIB system without FACTS device 


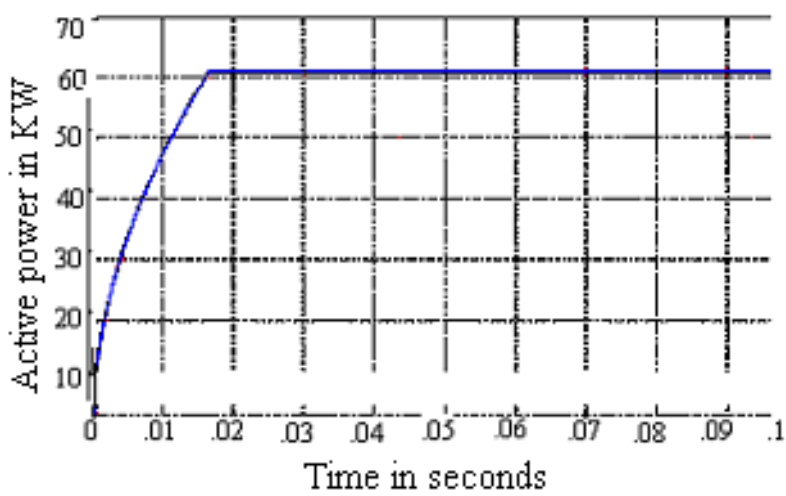

Fig. 14 Variation of receiving end active power with time for the SMIB system with UPFC

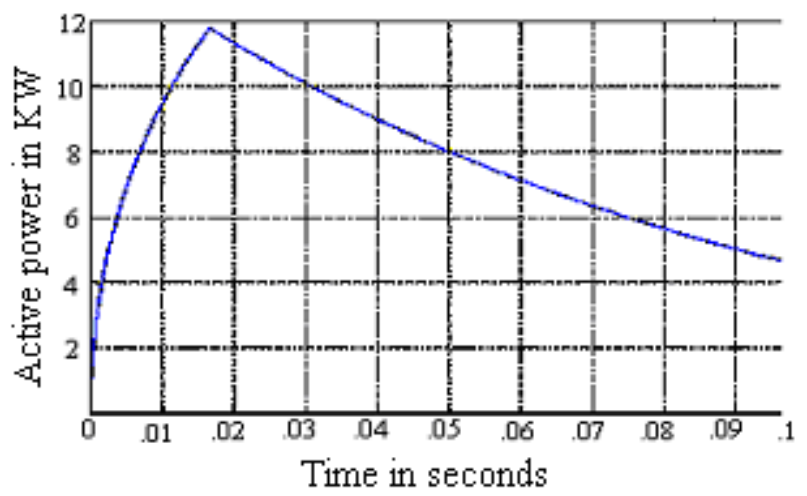

Fig. 15 Variation of receiving end active power with time for the SMIB system with SSSC

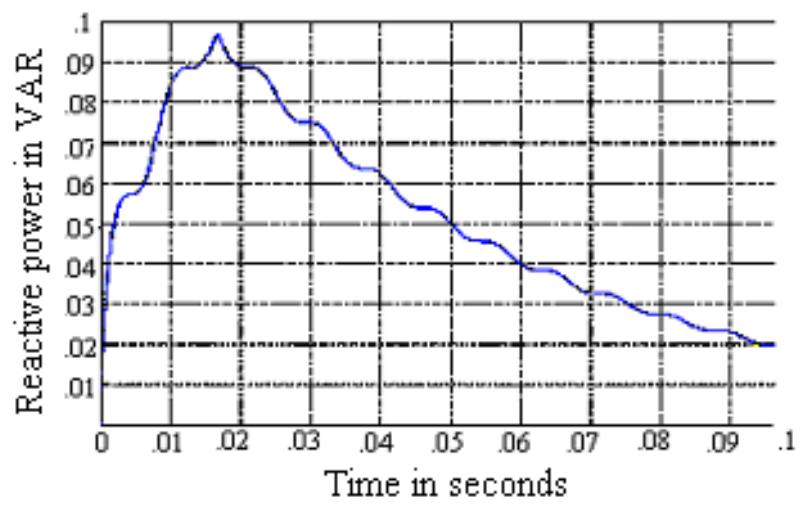

Fig. 16 Variation of receiving end reactive power with time for the SMIB system without FACTS device

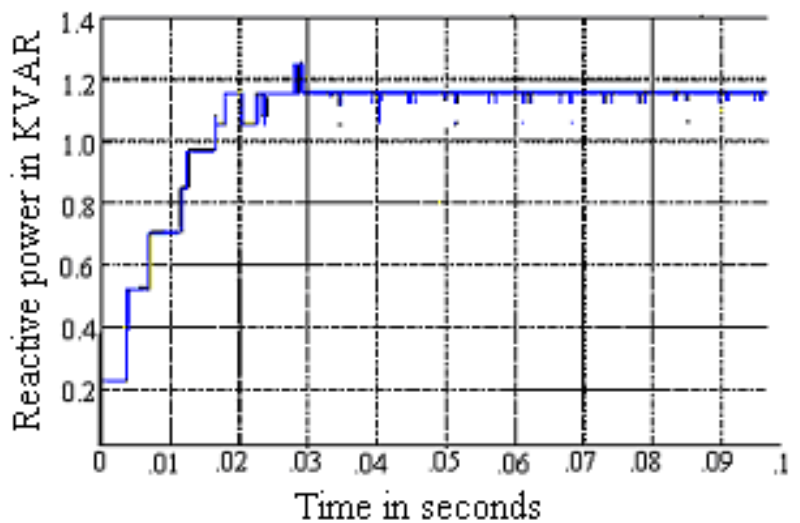

Fig. 17 Variation of receiving end reactive power with time for the SMIB system with UPFC

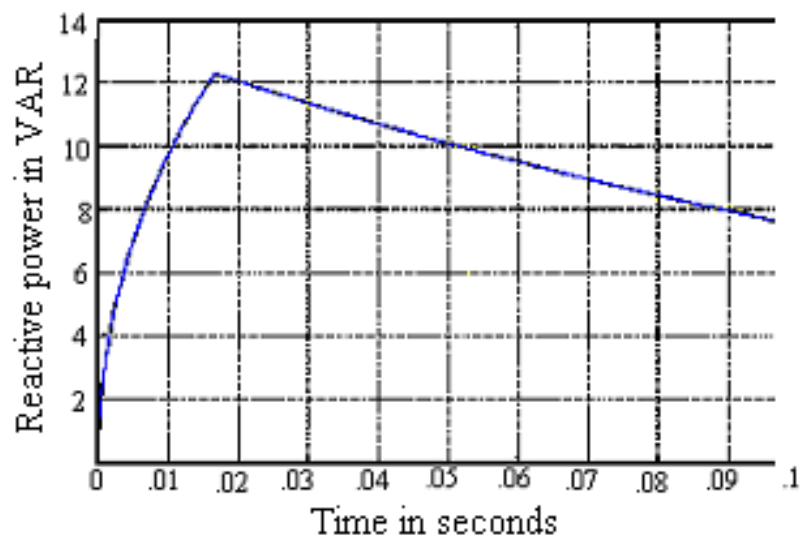

Fig. 18 Variation of receiving end reactive power with time for the SMIB system with SSSC

\section{CONCLUSION}

In this study, the Matlab/Simulink environment is used to simulate a simple single machine infinite bus (SMIB) power system with UPFC connected to a three phase three wire transmission system. The control and performance of UPFC intended for installation on a transmission line is presented. Simulation results show the effectiveness of UPFC on controlling the power angle oscillations and real and reactive power flow through the line. From the simulation results, it is inferred that there is an improvement in the real and reactive power flow through the transmission line with UPFC when compared to the system without UPFC and with SSSC.

\section{REFERENCES}

[1] N.G. Hingorani, 1988, "High Power Electronics and Flexible AC Transmission System”, IEEE Power Eng. REV.

[2] B.M. Zhang and Q.F. Ding, 1997, "The Development of FACTS and its Control", Proc. APSCOM-97, Hong Kong. 
[3] R.M. Mathur, R.K. Varma, 2002, "Thyristor-based FACTS Controllers for Electrical Transmission Systems," IEEE Press, Piscataway.

[4] K.K. Sen, 1998, "SSSC - Static Synchronous Series Compensator: Theory, Modeling and Application", IEEE Trans. on Power Delivery, 13(1), pp. 241-246.

[5] L. Gyugyi, 1994, "Dynamic Compensation of AC Transmission Line by Solid State Synchronous Voltage Sources," IEEE Transactions on Power Delivery, 9(22), pp. 904-911.

[6] Prechanon Kumkratug, Panthep Laohachai, 2007, "Direct Method of Transient Stability Assessment of a Power System with a SSSC," Journal of Computers, 2(8), pp. 7782.

[7] I. Musirin, N. Diamah, M. Radzi, M. Murtadha Othman, M. Khayat Idris, and T. Khawa Abdul Rahman, 2008, "Voltage Profile Improvement using Unified Power Flow Controller via Artificial Immune System", WSEAS Trans. on Power Systems, 3(4), pp. 194-204.

[8] L. Gyugyi, C.D. Schauder, S.I. Williams, T.R. Reitman, D.R. Torgerson, and A. Edris, 1995, "The Unified Power Flow Controller: A new approach to power transmission control", IEEE Trans. on Power Delivery, 10(2), pp. 10851097.

[9] M. Noroozian, L. Angquist, M. Ghandhari, G. Andersson, 1997, "Use of UPFC for Optimal Power Flow Control," IEEE Transactions on Power Delivery, 12(4), pp. 1629. 1634.

[10] B.A. Renz, A. Keri, A.S. Mehraben, C. Schauder, E. Stacey, I. Kovalsky, L. Gyugyi, and A. Edris, 1999, "AEP Unified Power Flow Controller Performance", IEEE Trans. on Power Delivery, 14(4), pp. 1374-1381.
[11] I. Papic, P. Zunko, and D. Povh, 1997, "Basic Control of Unified Power Flow Controller", IEEE Trans. on Power Systems, 12(4), pp. 1734-1739.

[12] P. Kumkratug, M.H. Haque, 2003, "Versatile Model of a Unified Power Flow Controller in Simple System," IEE Proc. Gener. Transm. \& Distrib., 150(2), pp. 155-161.

[13] L. Gyugui, 1992, “A Unified Power Flow Control Concept of Flexible AC Transmission Systems", IEE Proceedings-C, 139(4), pp. 323-331.

[14] Prechanon Kumkratug, 2009, "Application of UPFC to Increase Transient Stability of Inter-Area Power System," Journal of Computers, 4(4), pp. 283-287.

[15] J. Bian, D.G. Ramey, R.J. Nelson, and A. Edris, 1997, “A Study of Equipment Sizes and Constraints for a Unified Power Flow Controller", IEEE Trans. on Power Delivery, 12(3), pp. 1385-1391.

[16] H. Fujita, Y. Watanabe, and H. Akagi, 1999, "Control and Analysis of a Unified Power Flow Controller", IEEE Trans. on Power Electronics, 14(6), pp. 1021-1027.

[17] A.J.F. Keri, X. Lombard, and A.A. Edris, 1999, "Unified Power Flow Controller (UPFC): Modelling and Analysis", IEEE Trans. on Power Delivery, 14(2), pp. 648-654.

[18] S. Tara Kalyani and G. Tulsiram Das, 2008, "Simulation of Real and Reactive Power Flow Control with UPFC Connected to a Transmission Line", Journal of Theoritical and Applied Information Technology", 4(1), pp. 16-22.

[19] P. Kundur, 1994, "Power System Stability and Control," McGraw-Hill, New York. 